
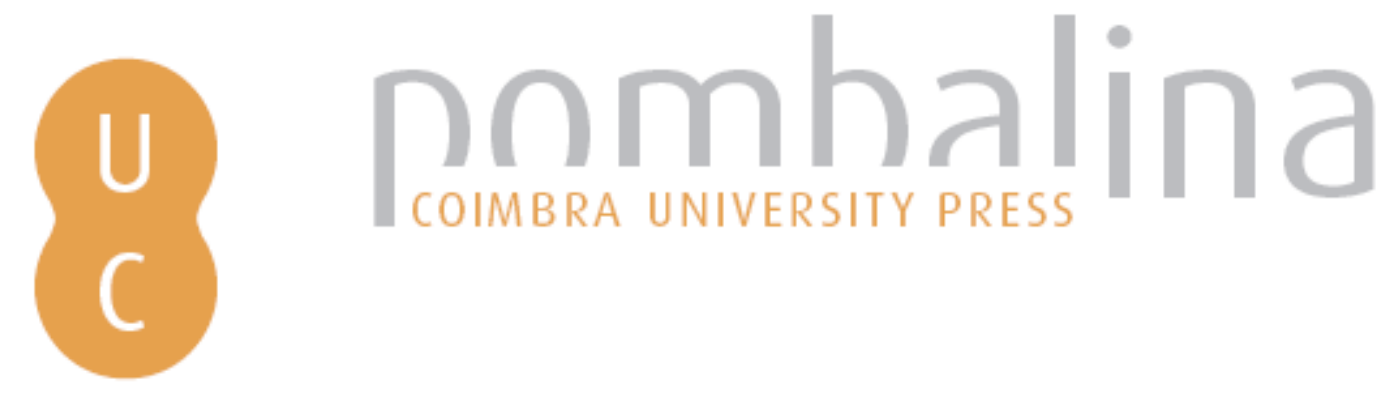

\title{
A escola e a ideologia colonial: contribuição para a formação das nacionalidades africanas de expressão portuguesa
}

Autor(es): $\quad$ Santos, Mariana Lagarto dos

Publicado por: Imprensa da Universidade de Coimbra

URL

persistente: URI:http://hdl.handle.net/10316.2/32142

DOI: $\quad$ DOI:http://dx.doi.org/10.14195/978-989-26-0339-1_3

Accessed : $\quad$ 26-Apr-2023 14:19:31

A navegação consulta e descarregamento dos títulos inseridos nas Bibliotecas Digitais UC Digitalis, UC Pombalina e UC Impactum, pressupõem a aceitação plena e sem reservas dos Termos e Condições de Uso destas Bibliotecas Digitais, disponíveis em https://digitalis.uc.pt/pt-pt/termos.

Conforme exposto nos referidos Termos e Condições de Uso, o descarregamento de títulos de acesso restrito requer uma licença válida de autorização devendo o utilizador aceder ao(s) documento(s) a partir de um endereço de IP da instituição detentora da supramencionada licença.

Ao utilizador é apenas permitido o descarregamento para uso pessoal, pelo que o emprego do(s) título(s) descarregado(s) para outro fim, designadamente comercial, carece de autorização do respetivo autor ou editor da obra.

Na medida em que todas as obras da UC Digitalis se encontram protegidas pelo Código do Direito de Autor e Direitos Conexos e demais legislação aplicável, toda a cópia, parcial ou total, deste documento, nos casos em que é legalmente admitida, deverá conter ou fazer-se acompanhar por este aviso. 


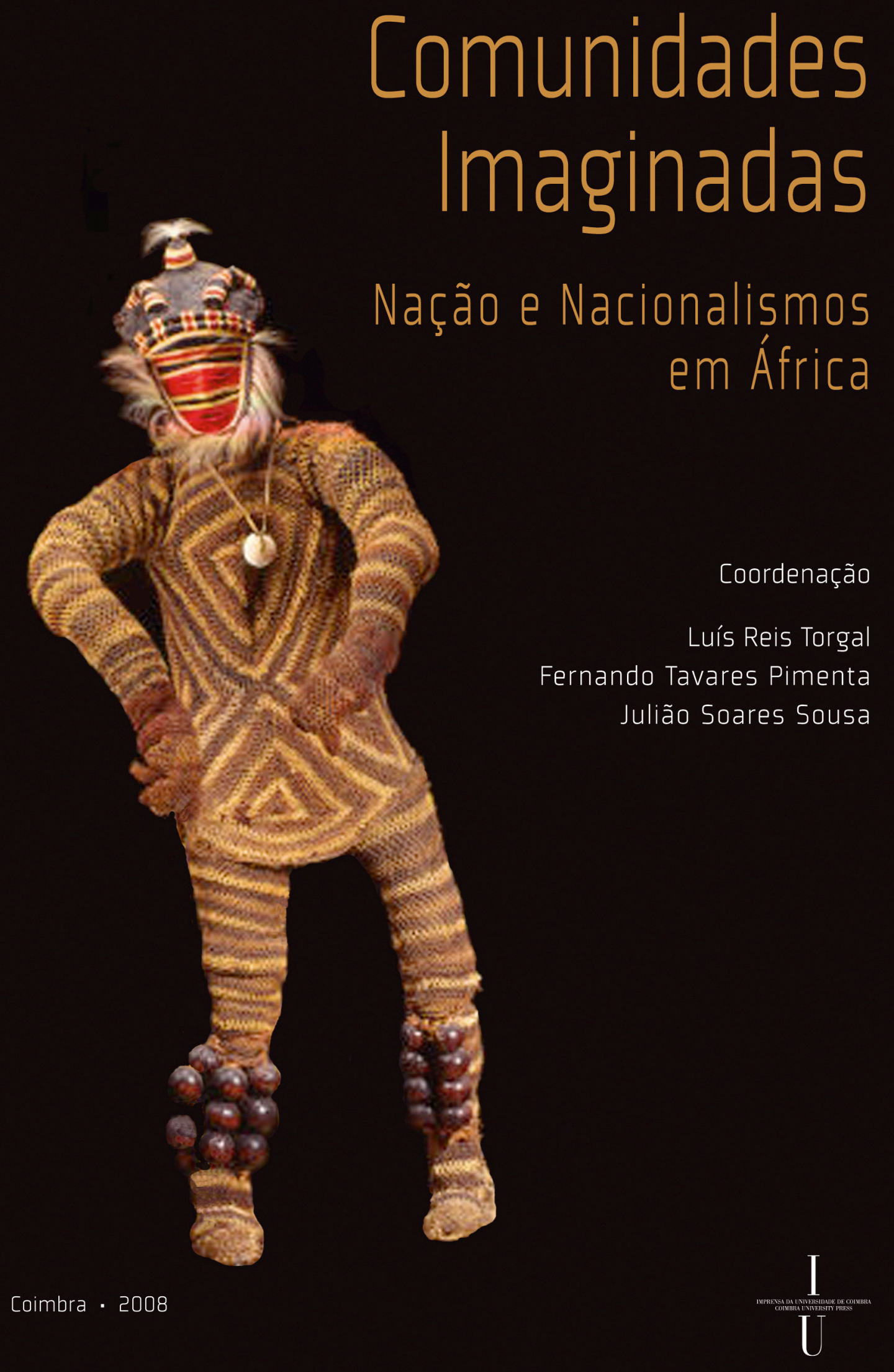




\title{
Comunidades Imaginadas \\ Nação e Nacionalismos em África
}

\author{
Coordenação \\ Luís Reis Torgal \\ Fernando Tavares Pimenta \\ Julião Soares Sousa
}

Coimbra $\cdot 2008$

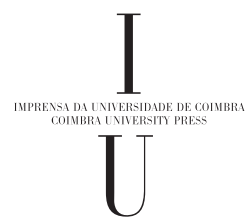




\begin{abstract}
COORDENAÇÃO EDITORIAL
Imprensa da Universidade de Coimbra

Email: imprensauc@ci.uc.pt

URL: http://www.uc.pt/imprensa_uc
\end{abstract}

CONCEPÇÃO GRÁFICA

António Barros

PAGINACÁO

Paulo Oliveira

[PMP]

EXECUÇÃO GRÁFICA

?????????????

ISBN

978-989-8074-57-7

DEPÓSITO LEGAL

????????????????????????

OBRA PUBLICADA COM A COLABORAÇÃO DE:

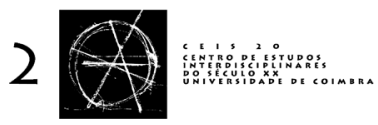

OBRA PUBLICADA COM O APOIO DE:

FCT Fundação para a Ciência e a Tecnologia

MINISTÉRIO DA CIÊNCIA, TECNOLOGIA E ENSINO SUPERIOR Portugal

Apoio do Programa Operacional Ciência, Tecnologia, Inovação do Quadro Comunitário de Apoio III 



\section{A ESCOLA E A IDEOLOGIA COLONIAL CONTRIBUiÇÁO PARA A FORMAÇÃO DAS NACIONALIDAdES AFRICANAS DE EXPRESSÃO PORTUGUESA.}

\section{Introdução}

A ideologia colonial, apesar dos contornos que foi assumindo ao longo de toda a

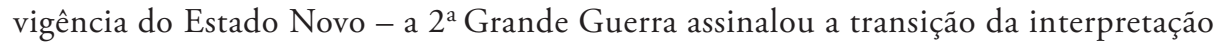
do colonialismo como apologia da Raça e como dever histórico, para uma de cariz luso-tropical - esteve ao serviço do desiderato, quer na metrópole quer nas colónias, da promoção da coesão nacional.

O sistema de ensino português, durante o período que medeia 1930 e 1974, desempenhou um papel fundamental na transmissão da ideologia colonial, tendo sido o manual escolar o instrumento privilegiado para esse efeito. A análise de textos relativos ao Portugal de além-mar, presentes em livros de leitura do Estado Novo (que na maioria dos casos eram os mesmos para as escolas metropolitanas e para as coloniais $^{1}$ ), permite-nos compreender o modo como foi sendo incutido, através da escola, o sentimento de unidade, ao qual se acrescenta, no caso das colónias, o de identificação com a "pátria” portuguesa, ao nível político, cultural e linguístico.

Neste sentido, será pertinente reflectir acerca do contributo da ideologia colonial para a formação das nacionalidades africanas de expressão portuguesa, que, apesar dos imprescindíveis apelos à africanidade, se construíram com base numa unidade forjada pelo regime contra o qual se opuseram. Não será por acaso que os manuais publicados pelo PAIGC, na Guiné, tenham sido redigidos em português: os mentores da construção de novos Estados-Nação compreenderam o poder unificador da língua de Camôes.

O presente texto consiste numa reflexão acerca de uma possível relação entre a "escola" do Estado Novo, enquanto difusora de uma ideologia e de uma cultura unificadas, e a formação das nacionalidades africanas de expressão portuguesa, ou seja, tem como objectivo fundamental abalançar o peso que a "educação colonial" possa ter tido no processo de construção dessas mesmas nacionalidades.

\footnotetext{
${ }^{1}$ Cf. Michel Cross, "The political economy of colonial education: Mozambique, 1930-1975”, em Comparative Education Review, vol.31, n. ${ }^{4}$ 4, 1987, pp. 550-569.
} 


\section{Um profundo amor à Pátria}

A expressão "educação colonial" assume um duplo sentido. Por um lado, é uma das dimensóes da "educação nacional" levada a cabo na metrópole; por outro, refere-se ao próprio sistema de ensino implementado nos territórios ultramarinos ${ }^{2}$.

$\mathrm{Na}$ metrópole, nos "anos fortes" do regime, o sistema educativo ao serviço da transmissão de uma ideologia colonial caracterizada pela "apologia" e defesa do colonialismo, cumpria a função de sublinhar a grandeza da Pátria pela divulgação da ideia de Império, louvar a Raça e o génio portugueses, assim como despertar o gosto pelos territórios ultramarinos com o fim de cativar potenciais colonizadores. Efectivamente, as colónias/províncias ultramarinas africanas constituíram um "bem" que urgia manter e preservar. Era, por isso, necessária a sua divulgaçáo e a consciencialização do povo português da sua importância.

O ensino para os autóctones não-brancos dos territórios ultramarinos, tinha como principais objectivos civilizar e unificar culturalmente. "Civilizar" na prática significava proporcionar a aprendizagem da língua portuguesa e dos rudimentos da religião católica, a aquisição de competências para os trabalhos rurais e manuais. $\mathrm{Na}$ realidade, não se pretendia criar entre os povos africanos elites letradas, mas sim torná-los "instrumentos" ao serviço de Portugal. Nesta perspectiva era necessário "unificar" culturalmente os povos, fazê-los sentirem-se portugueses, pelo que se afigurava importante promover o abandono de práticas tribais e a progressiva, lenta e limitada aproximação aos valores da civilização europeia. "Ler, escrever e contar" era o que a escola podia dar aos "indígenas". Desde a consolidação do Estado Novo (e mais propriamente a partir do Congresso do Ensino Colonial na Metrópole, em 1943) até à década de 50, o ensino estava dividido em ensino para africanos indígenas e ensino para assimilados, europeus e não africanos. O ensino para indígenas (criado em 1930) estava ao encargo das missóes católicas (cujo papel foi reforçado pelo Estatuto Missionário, de 1941). Estava dividido em ensino rudimentar ou de adaptação/primário elementar (a partir da década de 60), tendo como objectivo ensinar a língua portuguesa e o cristianismo a nativos, e em ensino primário, cuja última classe funcionava como admissão a outros níveis de ensino. O ensino para assimilados/europeus era constituído pelo ensino primário e liceal, em que o último ano era destinado aos que queriam seguir estudos superiores ${ }^{3}$.

À educação, ao serviço do Estado, cabia o papel de "modelar" a criança, de criar um "novo Homem”. Nas palavras de Salazar, proferidas em 1939: "A família e a escola devem imprimir nas almas em formação, de modo a que não mais se apaguem, aqueles altos e nobres sentimentos que distinguem a nossa civilização e profundo amor à Pátria, como o dos que a fizeram e pelos séculos fora a engrandeceram" ${ }^{4}$.

\footnotetext{
${ }^{2}$ Sobre este assunto ver : João Carlos Paulo, "Da «educação colonial portuguesa» ao ensino no Ultramar", em História da expansão portuguesa, dir. de Francisco Bethencourt e Kirti Chaudruri, vol.5, Lisboa, Temas e Debates, 2000, pp. 304-333.

3 Cf. Brazão Mazula, Educação, cultura e ideologia em Moçambique : 1975-1985 : em busca de fundamentos filosófico-antropológicos, Lisboa, Ediçôes Afrontamento, D.L., 1995; Martins Santos, História do ensino em Angola, Luanda, Serviços provinciais de educação, 1970.

${ }^{4}$ Salazar, Discurso e Notas Politicas, 1928-1943,3ª ed., vol. IV, Coimbra, Coimbra Editora, 1939, p. 309.
} 
"O profundo amor à Pátria" deveria ser partilhado por todos aqueles que habitavam os territórios ultramarinos. As populaçôes não-brancas deveriam sentir-se parte integrante de uma Nação gloriosa, portugueses de "corpo e alma". Assim, nesses territórios, a educação procurou cumprir o desiderato de estimular o "orgulho de se ser português" e criar laços de uniáo entre todos os "portugueses". Após o eclodir da $2^{\text {a }}$ Guerra Mundial tornava-se ainda mais urgente a promoção do sentimento de pertença à "grande naçáo portuguesa", razáo pela qual se assiste a um maior investimento na educaçấo nos territórios africanos.

\section{Africanos de Portugal, portugueses de África}

No período pós-2a Guerra Mundial, e mais especificamente na década de 60, com eclodir da Guerra Colonial, verificou-se uma mudança de rumo na ideologia e política colonial do Estado Novo. Perante uma nova conjuntura internacional que condenava a prática colonialista (a ONU reconhecia entáo o direito dos povos à autodeterminação) havia que rever os fundamentos do colonialismo português, por uma questáo de sobrevivência do regime e de reabilitaçáo da sua "imagem" no quadro internacional. Uma vez que as colónias africanas eram importantes pilares económicos do país, e também políticos e ideológicos, a sua independência estava fora de causa. A partir da década de 50 assiste-se a uma "viragem para sul", tendo sido os territórios africanos alvo de planos de fomento e de algum investimento privado 5 , e a par de uma revisão constitucional, a reformulaçáo dos pressupostos ideológicos do colonialismo era levada a cabo. Em 1951 o Acto Colonial (1930) é revisto e passa a integrar a Constituição. Em vez de colónias, os territórios de além-mar passavam a designar-se de "províncias", à semelhança do Minho ou Ribatejo. Portugal deixava assim de ser um Império para se tornar uma Nação multirracial e pluricontinental. Esta mudança jurídica foi acompanhada de uma mudança do suporte ideológico do Colonialismo/Imperialismo vigente nos anos 30 e 40, verificando-se, a partir da década de 50, e com mais expressividade nos anos 60 , a adopção da doutrina do Luso-tropicalismo, criada pelo sociólogo brasileiro Gilberto Freire. Substituto da "mística imperial", o Luso-tropicalismo vai funcionar como a legitimação científica e justificação ideológica para uma nova política ultramarina: sublinha a singularidade da colonização portuguesa, exemplar porque pacífica, tolerante, propensa à fusão de culturas e mestiçagem, e enaltece as supostas aptidóes colonizadoras do português, portador de características que lhe permitiam uma perfeita comunhão com o ambiente, sociedade e cultura tropicais ${ }^{6}$.

De acordo com a divisa "Muitas raças, um só Povo", Moçambique, Angola, Cabo Verde, etc. eram Portugal, e os seus autóctones, portugueses. Esta situação foi corroborada legalmente pela abolição do Regime de Indigenato (em 1961, com

\footnotetext{
${ }^{5}$ Ver Fernando Rosas," O Estado Novo", em História de Portugal, dir. José Mattoso, vol, VII, Lisboa, Estampa, 1994.

${ }^{6}$ Sobre este assunto ver o trabalho de Cláudia Castelo, O modo português de estar no mundo. O lusotropicalismo e a ideologia colonial portuguesa (1933-1961), Porto, Afrontamento, 1999.
} 
Adriano Moreira na pasta das colónias), ou seja, passou a reconhecer-se a cidadania portuguesa a todos os habitantes dos territórios ultramarinos ${ }^{7}$.

A escola salazarista vai adaptar-se às novas circunstâncias. Na Metrópole, o discurso acentua a originalidade da colonização portuguesa, pacífica, amistosa, desejada pelos povos africanos. Pode ler-se num texto de um Livro de Leituras da História de Portugal, editado em 1951 e destinado às escolas metropolitanas, com textos de António Gonçalves Mattoso: "Há poucos anos, um jornalista francês visitou a nossa província de Moçambique. Tendo visto um soldado negro, cujo aspecto o impressionou pela maneira digna como se apresentava, perguntou-lhe a que raça pertencia. $\mathrm{O}$ negro perfilou-se e respondeu com orgulho: - "sou português". Esta resposta, concluiu o viajante, sai-lhe do coração. (...) Não era a primeira vez que ouvia um preto, aclamar assim, com orgulho obstinado, a sua nacionalidade de adopção" 8

Nas províncias ultramarinas era ainda mais urgente criar uma ideia de "cultura unificada", fazer com que todos se sentissem portugueses, principalmente a partir da década de 60. Para tal era necessário um maior investimento na educação, um aumento da rede escolar no que diz respeito ao ensino elementar e secundário?.

Num tempo em que os movimentos de libertação passavam à acção, ganhando cada vez mais terreno, era prioritário reforçar o laço que supostamente existia entre Portugal e África. No fundo, acreditava-se que, como referiu Eduardo Mondlane, figura de proa da FRELIMO, no seu texto Luta por Moçambique, se através da educaçáo e da lei todos os africanos de Angola, Moçambique, Guiné-Bissau se tornassem portugueses, não haveria ameaça de nacionalismo africano ${ }^{10}$. Num livro de leitura da segunda classe utilizado na província da Guiné, em 1973, podia ler-se: "na minha casa há várias pessoas; eu, meu pai, minha mãe e os meus irmãos. Também é assim Portugal, a Pátria de todos nós. Como se fosse uma casa muito grande, nela vivem e trabalham portugueses de diferentes raças. E como uma casa tem várias divisóes, também Portugal tem terras espalhadas pelo mundo. Por isso falar da Guiné é a mesma coisa que falar de Portugal e amar a Guiné é amar Portugal. E eu, embora pequeno, gosto muito da minha Pátria e orgulho-me de ser português" ${ }^{11}$.

Este texto é apenas um exemplo do modo como se procurou forjar uma nova identidade para os povos africanos. Os manuais escolares utilizados nas províncias ultramarinas estavam repletos de alusóes à "Pátria Portuguesa" e aos seus símbolos.

\footnotetext{
${ }^{7}$ Para aprodundar este assunto consultar: Luís Reis Torgal, "Muitas raças, uma Nação ou o mito do Portugal multirracial na "Europa» do Estado Novo”, em Estudos do século XX, n², Coimbra, Quarteto, pp. 161-163.

${ }^{8}$ António G. Mattoso, Mar Português. Leituras da História de Portugal, Ensino técnico e profissional, $1^{\circ}$ ano, Lisboa, Livraria Sá da Costa, 1951, p. 286.

9 Sobre o assunto consultar: Sobre este assunto ver : João Carlos Paulo, "Da «educação colonial portuguesa" ao ensino no Ultramar", em História da expansâo portuguesa, dir. de Francisco Bethencourt e Kirti Chaudruri, vol.5, Lisboa, Temas e Debates, 2000, pp. 304-333; Cf. Brazão Mazula, Educação, cultura e ideologia em Moçambique : 1975-1985 : em busca de fundamentos filosófico-antropológicos, Lisboa, Ediçóes Afrontamento, D.L., 1995; Martins Santos, História do ensino em Angola, Luanda, Serviços provinciais de educação, 1970.

${ }^{10}$ Eduardo Mondlane, Luta por Moçambique, Lisboa, Sá da Costa, col. Terceiro Mundo, 1975.

${ }^{11}$ Almeida Abrantes, Barros Pereira, O meu segundo livro de leitura, Porto, Ambar, Edição do Governo da Província da Guiné, 1973, p. 6.
} 
Na realidade, a história ensinada era a história de Portugal; a bandeira lusa e o mapa de Portugal figuravam lado a lado com imagens alusivas ao dia-a-dia das populaçóes africanas; aprendia-se o hino português e era explicada a sua importância. Nos manuais, os textos incentivavam à luta em nome da Pátria:
Soldado Valente
Sou um soldado valente
Sei defender Portugal
Com amor e devoção
De Português bem leal;
Mostrarei a toda a gente
O que vale um soldadinho
Muito aprumado e garboso
Que marcha assim direitinho.

Este poema, presente num livro de leituras para a $1^{\text {a }}$ classe, utilizado na província da Guiné, em 1970, terminava com a frase "O bom português honra e defende a sua Pátria"12.

Para estimular o sentimento de "amor à Pátria", Portugal era apresentado como uma nação esplendorosa, sendo narrados os factos e acontecimentos que a "santificavam" - o milagre de Fátima era contado às crianças de Moçambique, num manual de $1970^{13}$ - e a engrandeciam Tendo em conta o mesmo objectivo, e procurando apresentar os portugueses como um povo desprovido de racismo, nos manuais escolares utilizados nas escolas primárias e liceus em África podiam ler-se palavras de estímulo à união de irmãos negros, mestiços e brancos, ambos construtores do futuro da Pátria comum. Exemplo disso é o seguinte poema de um livro de leitura para as escolas de Angola, editado em $1969^{14}$ :
Rumo ao Futuro
Lado a lado, devagar,
Caminham
Dois meninos
Direitos à escola!
Um preto e outro branco!
Há neste um riso doirado,
E há naquele um olhar franco!
Alegres ambos, felizes,
Coração puro, inocente,
Lá seguem, rumo ao futuro,
A caminho da escola.

\footnotetext{
${ }^{12}$ Almeida Abrantes, Barros Pereira, O meu primeiro livro de leitura, Porto, Ambar, Edição do Governo da Província da Guiné, 1970.

${ }^{13}$ S.a., O meu companheiro, Livro de Letura para a $2^{a}$ Classe, s.l., Ambar, Editado pelo Governo da Província de Moçambique, 1970.

${ }^{14}$ S.a., Velas de Cristo - Livro de Leitura da $3^{a}$ Classe, Porto, Ediçóes ABC, 1965, p.117.
} 
E escrevem ambos, a par,

A história linda de Angola!

\section{Nação Portuguesa, Naçốes Africanas}

Partindo da ideia de que uma nação se define pela existencia de um território compacto e bem definido, cujos habitantes partilham os mesmos valores e tradiçóes e uma ideologia cívica comum, podemos afirmar que as "naçôes" africanas por cuja libertação se constituíram movimentos, não existiam enquanto "nações" antes do colonialismo português. Nos territórios referidos coexistiam diversas etnias, cada qual com a sua língua, costumes, hierarquias e até territorialidades próprias. Acresce ainda que, se a identidade nacional implica uma consciência de comunidade política, cujos membros obedecem a um código de leis comum, bem como de orgáo para o seu cumprimento podemos afirmar que na áfrica colonial essa identidade não existia ${ }^{15}$.

Foi em parte a escola ao serviço da ideologia colonial, ao intentar criar uma unidade/identificação cultural entre metrópole e territórios ultramarinos, que forneceu aos vários povos elementos aglutinadores essenciais à formação de uma nova identidade nacional: contribuiu, assim, para a formação de novas nacionalidades africanas de expressão portuguesa.

Para que os movimentos de libertação se constituíssem como movimentos nacionalistas era necessário "criar uma nação". As "novas nações africanas" foram-se "imaginando" a si próprias a partir de elementos fornecidos pelo colonialismo: o território, a língua, o sentimento de pertença a um grupo mais vasto, que ultrapassasse a heterogeneidade étnica característica de cada domínio colonial.

Assim, o colonialismo, através do seu sistema de ensino, promoveu a consciencialização da territorialidade própria de cada extensão do Império. Na realidade, o colonialismo não só criou as fronteiras dos territórios ultramarinos, mas também contribuiu para que os povos que os habitavam se consciencializassem da existência desse mesmo território, através da sua concretização como realidade "palpável”, objectiva, conseguida pela sua visualização em mapas e imagens presentes nos manuais.

A utilização da Língua Portuguesa como idioma nacional teve também um efeito homogeneizador. Por exemplo, Amílcar Cabral não abdicou da ideia do português como "língua nacional" ao fazer o livro de leitura para o PAIGC, a utilizar nas zonas libertadas, afinal como forma de unificar as cerca de trinta etnias existentes na Guiné.

A escola promoveu também o aparecimento da consciência de identidade, de pertença a um novo grupo. Em muitos manuais utilizados nas províncias ultramarinas, era reforçada a ideia de pertença a Angola, a Moçambique ou a Guiné, com a intenção de reforçar a pertença Portugal. Contudo, isso provocou a consciencialização de se ser Angolano, Moçambicano ou Guineense. Efectivamente, o apelo à nacionalidade em

${ }^{15}$ Estes elementos enquadram-se na "modelo cívico de Nação", segundo a categorização de Anthony Smith (ver Anthony Smith, Nacionalismo: teoria, ideologia, história, Lisboa, Teorema, 2006). De acordo com o autor, os países africanos que se libertaram do jugo colonial procuram adoptar-se a este modelo ocidental de Estado-Nação. 
cada zona da África de expressão portuguesa passou, não pelo o apelo à especificidade de cada grupo étnico nela existente, mas à união de todas essas diferenças sob a tutela de uma identidade (ser Angolano e não Ovibumdo ou Bakongo, ser Moçambicano e não Macua ou Maconde, ser Guineense e não Balanta ou Mandinga). Por isto não é de estranhar que na proclamação feita ao povo de Moçambique em 1964, Mondlane se tenha dirigido ao "povo" de Moçambique, e não aos "povos" de Moçambique 16 .

Parece ter sido ponto assente entre os dirigentes dos movimentos de libertação, logo após a independência, a ideia de que, para que a nação se tornasse una e coesa não podiam ser feitas concessóes à etnicidade. Isso poderia prejudicar a ideia de pertença a uma determinada naçáo, ideia essa que seria o trampolim para o sentimento de pertença a um Estado. Como defende Basil Davidson, a nação em África é mais um projecto nacional que anima um programa político ${ }^{17}$. Para tal havia que se levar a cabo uma uniformizaçáo cultural. Por exemplo, o MPLA, apesar de inicialmente ter feito concessóes à etnicidade, acabou por as suprimir na proposta de lei constitucional da República Popular de Angola, em 1965 ${ }^{18}$. A criação de uma nacionalidade era importante também na medida em que evitaria a possibilidade de instrumentalização dos vários grupos étnicos, nalguns casos, por facçôes que pretendessem usurpar o poder. A defesa do partido único, nos territórios uma vez libertos, era um modo de assegurar a coesão nacional em vez de acicatar as lutas partidárias, por vezes tribalistas ${ }^{19}$.

Pode por último dizer-se que o colonialismo acaba por dar o mote à reivindicação nacionalista: em última instância o nacionalismo africano de expressão portuguesa poder-se-á definir como uma a luta do povo contra o governo colonial. A ideia é a de que o colonialismo foi uma faca de dois gumes: o sistema educativo ao seu serviço, ao propalar a pertença a uma Nação - Portugal - acabou por acicatar a revolta contra essa mesma Nação. A luta contra o "inimigo comum" acaba por suprir a falta de uma identidade resultante da inexistência de recordaçóes históricas comuns, símbolos ou tradiçôes.

Há ainda que acrescentar que o aparecimento de uma "consciência nacional" não terá sido uniforme nem profundo em todo o território africano. $\mathrm{O}$ acesso à educação não foi uma realidade para a maioria das populaçôes não-brancas das colónias, havendo um grande fosso entre o que se passava nas zonas rurais e nas zonas urbanas, sendo que nas zonas rurais muitos dos indígenas (indivíduos náo brancos que ainda não tinham sido assimilados, ou seja, ainda não tinham passado pelo processo educativo que os conduziria a uma aproximação, por muito ligeira que na verdade tenha sido, aos parâmetros da civilização ocidental) não recebiam mais instrução do que cristã, através das missóes. Mas nas zonas urbanas a situação diferia um pouco, sendo que as

\footnotetext{
${ }^{16}$ Ver Eduardo Mondlane Mondlane, Eduardo, Luta por Moçambique, Lisboa, Sá da Costa, col. Terceiro Mundo, 1975.

${ }^{17}$ Cf. Basil Davidson,, O fardo do homem negro: os efeitos do estado-nação em África, Porto, Campo de Letras, 2000.

${ }^{18}$ M. L. Rodrigues de Areia, "A etnicidade como processo", em O desafio Africano: actas do colóquio "África de língua portuguesa: presente e futuro", org. Universidade da Beira Interior, coord. José Carlos Venâncio, Lisboa, Vega, 1997, pp. 27-43.

${ }^{19}$ Cf. Yves Benot, Ideologias das independências africanas, Sá da Costa, Lisboa, 1981.
} 
populaçôes assimiladas, "crioulas" (bilingues), recebiam educação oficial, podendo aceder ao ensino liceal e posteriormente ao ensino superior ${ }^{20}$. Mas na realidade foram estas elites urbanas que encabeçaram os movimentos nacionalistas e a quem coube a tentativa de modelação de uma consciência nacional, se não mesmo de uma $\mathrm{Naçáo}^{21}$.

\section{Conclusão}

Em suma, a formação das nacionalidades africanas de expressão portuguesa foi, em parte, fruto do colonialismo. Foi a própria ideologia colonial que permitiu que as colónias se imaginassem como Naçôes, ao possibilitar-lhes a consciencialização que detinham um território, uma língua e um povo.

\section{Bibliografia}

ALMEIDA ABRANTES, Barros Pereira, O meu primeiro livro de leitura, Porto, Ambar, Edição do Governo da Província da Guiné, 1970.

AMARAL, Ilídio do, Em torno dos nacionalismos africanos: memórias e reflexôes em homenagem a Mário Pinto de Andrade(1928-1990), Porto, Granito editores e Livreiros, Centro de Estudos Africanos da Universidade do Porto, 2000.

ANDERSON, Benedict, Comunidades imaginadas. Reflexōes sobre a origem e a expansão do nacionalismo, Lisboa, Edicóes 70, Perspectivas do Homem, 2005.

ANDRADE, Mário Pinto de, Origens do nacionalismo Africano: continuidade e ruptura nos movimentos unitários emergentes da luta contra a dminaçáo colonial Portuguesa: 1911-1961, Lisboa, Publicaçôes D. Quixote, 1997.

BENOT, Yves, Ideologias das independências africanas, Sá da Costa, Lisboa, 1981.

BETHENCOURT, Francisco e Kirti Chaudruri (dir. de), História da expansão portuguesa, vol.5, Lisboa, Temas e Debates, 2000.

CASTELO, Cláudia, O modo português de estar no mundo. O luso-tropicalismo e a ideologia colonial portuguesa (1933-1961), Porto, Afrontamento, 1999.

CROSS, Michel, "The political economy of colonial education: Mozambique, 1930-1975", em Comparative Education Review, vol.31, no.4, 1987, pp. 550-569.

DAVIDSON, Basil, O fardo do homem negro: os efeitos do estado-nação em África, Porto, Campo de Letras, 2000.

GELLNER, Ernst, Nações e Nacionalismo, Lisboa, Gradiva, 1993.

GRAÇA, Pedro Borges, A construção da Nação em África, Coimbra, Almedina, 2005.

MATEUS, Dalila Cabrita, A luta pela indepedência: a formação das elites fundadoras da Frelimo, MPLA e PAIGC, Mem Martins, Inquérito, 1999.

MATTOSO, José (dir. de), História de Portugal, vol. VII, Lisboa, Estampa, 1994.

\footnotetext{
${ }^{20}$ Sobre este assunto ver Brazão Mazula, Educação, cultura e ideologia em Moçambique: 1975-1985: em busca de fundamentos filosófico-antropológicos, Lisboa, Ediçóes Afrontamento, D.L., 1995.

${ }^{21}$ Sobre este assunto ver Dalila Cabrita Mateus Mateus, Dalila Cabrita, A luta pela indepedência: a formação das elites fundadoras da Frelimo, MPLA e PAIGC, Mem Martins, Inquérito, 1999.
} 
ANTÓNIO G. MATTOSO, Mar Português. Leituras da História de Portugal, Ensino técnico e profissional, 1º ano, Lisboa, Livraria Sá da Costa, Lisboa, 1951.

MAZULA, Brazão, Educação, cultura e ideologia em Moçambique: 1975-1985: em busca de fundamentos filosófico-antropológicos, Lisboa, Edições Afrontamento, D.L., 1995.

MONDLANE, Eduardo, Luta por Moçambique, Lisboa, Sá da Costa, col. Terceiro Mundo, 1975.

MOREIRA, Adriano; Venâncio, José Carlos, Luso-tropicalismo: uma teoria social em questão, Lisboa, Vega, 2000.

O desafio Africano: actas do colóquio "África de lingua portuguesa: presente e futuro", org. Universidade da Beira Interior, coord. José Carlos Venâncio, Lisboa, Vega, 1997.

OLIVEIRA, Mário António Fernandes, ”Á procura de uma identidade cultural Angolana: do Liceu Salvador Correia à sociedade cultural de Angola”, em Revista Internacional de Estudos Africanos, nos. 6 e 7, Janeiro-Dezembro, 1987, pp. 179-194.

ROSA, Manuel Ferreira, O ponto e o rumo do ensino ultramarino. Testemunhos do pensamento e acção, Angola, Lello, 1973.

ROSA, Vitor Ferreira da, Pós-colonialismo e identidade, Porto, Univrsidade Fernando Pessoa, 1998.

SANTOS, Martins, História do ensino em Angola, Luanda, Serviços provinciais de educação, 1970.

SILVA, Elisete Marques da, "O papel societal do sistema de ensino da Angola colonial, (19261974)", em Revista Internacional de Estudos Africanos, n. ${ }^{\text {os }}$ 16-17, pp. 103-130.

SMITH, Anthony, Nacionalismo: teoria, ideologia, história, Lisboa, Teorema, 2006.

TORGAL, Luís Reis "Muitas raças, uma Naçáo ou o mito do Portugal multirracial na "Europa" do Estado Novo", in Estudos do século XX, n. ${ }^{\circ}$ 2, Coimbra, Quarteto, pp. 161-163.

S.A., O meu companheiro, Livro de Letura para a $2^{a}$ Classe, s.l., Ambar, Editado pelo Governo da Província de Moçambique, 1970.

S.A., Velas de Cristo - Livro de Leitura da 3a Classe, Porto, Edições ABC, 1965, p.117. 


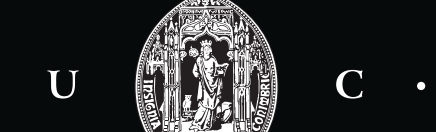

